\title{
INTERNET: CONFLITOS DE PRINCÍPIOS FUNDAMENTAIS
}

\author{
INTERNET: CONFLICTS OF FUNDAMENTAL PRINCIPLES
}

\author{
Bruna Pinotti Garcia; Mário Furlaneto Neto*
}

\begin{abstract}
Sumário: Introdução. 1 Evolução do Constitucionalismo. 2 Internet: origens e colisões de princípios. 3 Particularidades da Internet: das necessárias flexibilização normativa e compatibilidade moral. 4 Soluções do neoconstitucionalismo para as colisões de princípios fundamentais na Internet. Conclusões. Referências.
\end{abstract}

\begin{abstract}
Resumo: A evolução da sociedade faz com que o Direito sofra paulatinamente modificações. Observa-se três períodos marcantes no âmbito do direito constitucional: Jusnaturalismo, Positivismo e Pós-positivismo. Hoje o Direito está na última destas fases, também chamada de Neoconstitucionalismo, na qual a Hermenêutica Constitucional ganhou novos rumos com a força normativa dos princípios. Dentro deste contexto, o presente artigo aborda os conflitos decorrentes da Internet, bem como as particularidades deste mecanismo. Em suma, discute-se sobre como a intensificação de colisões de princípios fundamentais, além dos elementos referentes ao fluxo e a desterritorialização das informações da $W e b$, implicam na necessidade de uma maior flexibilização normativa e aceitação social do Direito imposto com relação aos conflitos da Internet, destacando ainda como é possível atingir tais objetivos.
\end{abstract}

Palavras-chave: Internet. Neoconstitucionalismo. Direitos fundamentais. Colisão de princípios. Proporcionalidade.

\begin{abstract}
The evolution of society makes Law suffer gradually changes. It observes three periods marked within the constitutional right: Jusnaturalism, Positivism and Post-positivism. Today the Law is at the last of these phases, also named of Neoconstitucionalism, which the Constitucional Hermeneutic gained new directions with the normative force of principles. Inside these context, the present article approaches the conflicts arising the Internet, such as the particularities of these mechanism. In short, is discuss about how the intensification of fundamental principles collisions, beyond the elements referring to the flow and the e a deterritorialization of the Web information, implies at the necessity of a greater regulatory flexibility and the social acceptance of the forced Law in relation to the conflicts of the Internet, also emphasizing how is possible achieve these goals.
\end{abstract}

Keywords: Internet. Neoconstitucionalism. Fundamental rights. Principles collisions. Proportionality.

\section{Introdução}

A evolução da sociedade implica em mudanças acerca da percepção do Direito pela sociedade. Tanto é verdade que as principais transições jusfilosóficas foram marcadas por acontecimentos históricos relevantes. No presente artigo, um marco histórico que assume relevante importância é o do encerramento da Segunda Guerra Mundial, que deu origem ao movimento jurídico do Neoconstitucionalismo ou Póspositivismo.

O Pós-positivismo rompeu com as amarras da dogmática pura do Positivismo, a ponto de não promover, tão somente, um mero resgate do direito natural, mas, sim, colocar os princípios éticos e jurídicos na posição de norma. Assim, deixaram de ser um simples argumento complementar ou retórico, ganhando aplicabilidade imediata nos casos concretos em que as regras do ordenamento jurídico forem insuficientes. A hermenêutica constitucional ganhou nova tônica, o que influenciou diretamente no modo de aplicação do Direito pelos Tribunais.

Recentemente, no Brasil, esta nova postura do Judiciário tem ganhado cada vez mais destaque com as decisões do Supremo Tribunal Federal de grande repercussão. Esta posição ativa do Poder Judiciário é um tema delicado, com aspectos positivos e negativos, mas possui a vantagem de tornar o Direito mais dinâmico e condizente com o sistema de valores sociais.

\footnotetext{
*Bruna Pinotti Garcia é Mestre em Direito do Centro Universitário Eurípides de Marília - UNIVEM e aluna pesquisadora do "Núcleo de Estudos e Pesquisas em Direito e Internet - NEPI". Mário Furlaneto Neto é Doutor em Ciência da Informação pela Universidade Estadual Paulista - UNESP, professor de graduação e do Mestrado em Direito do Centro Universitário Eurípides de Marília - UNIVEM e coordenador do "Núcleo de Estudos e Pesquisas em Direito e Internet - NEPI".
} 
Dinamismo e alto índice de aceitação social são elementos cada vez mais necessários na sociedade contemporânea: informatizada e globalizada. O intenso fluxo de informações, a maneira como a sociedade é intensamente atingida por tal fluxo, as constantes alterações nos modos de relacionamentos e os inúmeros novos conflitos jurídicos que surgem diariamente são fatores facilmente perceptíveis e que implicam numa necessária mudança do modo de se aplicar o Direito.

Notadamente na Internet, percebe-se o grande volume de novas situações jurídicas não regulamentadas especificamente pelo Direito, demandando solução por parte do Poder Judiciário. De outro lado, a dinâmica da rede impossibilita uma aplicação uniforme e justa do Direito se o legislador partir para uma busca constante de reformas legislativas. Neste ponto, o Neoconstitucionalismo abre novas possibilidades no tocante a uma flexibilização no modo de se encarar o sistema jurídico, tornando-o cada vez mais apto a exteriorizar os clamores presentes desde o cerne da sociedade, atingindo uma gama infinita de soluções de conflitos.

A partir desse contexto, por meio de uma revisão bibliográfica, pretende-se efetuar alguns apontamentos iniciais de um tema tão complexo que é o da solução dos conflitos de princípios fundamentais no ciberespaço, partindo da hipótese de que o movimento Neoconstitucionalista está apto a fornecer um novo modo de resolução das situações jurídicas da rede mundial de computadores, mais dinâmico, flexível, eficaz e compatível com os valores morais.

\section{EVOLUÇÃO DO CONSTITUCIONALISMO}

Como asseverado introdutoriamente, o Direito Constitucional ou, por assim dizer, a teoria dos princípios, passou por fases distintas no decorrer da evolução social. Aborda a evolução constitucionalista de modo concomitante com os variados tratamentos da questão principiológica porque os princípios compõem o cerne do direito constitucional, sendo que o modo como eles são encarados na pirâmide normativa definem a importância que será dada ao ramo constitucionalista, colocando-o à margem ou no centro do sistema.

\footnotetext{
A juridicidade dos princípios passa por três distintas fases: a jusnaturalista, a positivista e a pós-positivista. A primeira - a mais antiga e tradicional - é a fase jusnaturalista; aqui, os princípios habitam ainda esfera por inteiro abstrata e sua normatividade, basicamente nula e duvidosa, contrasta com o reconhecimento de sua dimensão ético-valorativa de idéia que inspira os postulados de justiça. [...] Cedeu lugar, em seguida, a um positivismo tão forte, tão dominante, tão imperial, que ainda no século XX os cultores solitários esparsos da doutrina do Direito Natural nas universidades e no meio forense pareciam se envergonhar do arcaísmo de professarem uma variante da velha metafísica jurídica. [...] A ressurreição do jusnaturalismo produziu no século XX, sobretudo na Alemanha, reflexões curiosas, que talvez expliquem a tenacidade com que muitos juristas de aferram a essa doutrina do "eterno retorno" (BONAVIDES, 2011, p. 259-261).
}

Assim, a fase Pós-positivista é vista por alguns como um retorno ao Direito Natural. Contudo, se, por um lado, nela se resgatam valores éticos e jurídicos tradicionais na sociedade, por outro lado, a consubstanciação destes na forma escrita das Constituições os confere a força normativa. Trata-se de diferença fundamental, pois quando um princípio é considerado uma norma, tal qual uma regra, poderá ser aplicado de maneira exclusiva para a solução de litígios, geralmente adotando-se um critério de ponderação. 
Vale lembrar que a distinção entre regras e princípios é uma distinção entre dois tipos de normas, fornecendo juízos concretos para o dever ser. A diferença essencial é que princípios são normas de otimização, ao passo que regras são normas que são sempre satisfeitas ou não. Se as regras se conflitam, uma será válida e outra não. Se princípios colidem, um deles deve ceder, embora não perca sua validade e nem exista fundamento em uma cláusula de exceção, ou seja, haverá razões suficientes para que em um juízo de sopesamento um princípio prevaleça. (ALEXY, 2011, p. 91-94). Enquanto adepto da adoção de tal critério de equiparação normativa entre regras e princípios, o jurista alemão Robert Alexy é colocado entre os nomes do pós-positivismo (BONAVIDES, 2011, p. 266).

Com efeito, na fase Positivista, os princípios entravam nos Códigos apenas como válvulas de segurança, eram meras pautas programáticas supralegais, não possuindo normatividade; ao passo que na fase Pós-positivista, as Constituições destacam a hegemonia axiológica dos princípios, transformando-os em pedestal normativo que dá base a todo edifício jurídico dos novos sistemas constitucionais (BONAVIDES, 2011, p. 262-264).

Os princípios constitucionais, portanto, explícitos ou não, passam a ser a síntese dos valores abrigados no ordenamento jurídico. Eles espelham a ideologia da sociedade, seus postulados básicos, seus fins. Os princípios dão unidade e harmonia ao sistema, integrando suas diferentes partes e atenuando tensões normativas. De parte isto, servem de guia para o intérprete, cuja atuação deve pautar-se pela identificação do princípio maior que rege o tema apreciado, descendo do mais genérico ao mais específico, até chegar à formulação da regra concreta que vai reger a espécie. Estes os papéis desempenhados pelos princípios: a) condensar valores; b) das unidade ao sistema; c) condicionar a atividade do intérprete. Na trajetória que os conduziu ao centro do sistema, os princípios tiveram de conquistar o status de norma jurídica, superando a crença de que teriam uma dimensão puramente axiológica, ética, sem eficácia jurídica ou aplicabilidade direta e imediata (BARROSO, 2003, p. 327).

Não se pode, assim, perder de vista que no Neoconstitucionalismo ocorre a positivação nas Constituições de princípios tradicionalmente afirmados no direito natural, sendo que estes consolidam valores éticos da sociedade. Então, a partir do momento em que os conflitos são solucionados fundamentalmente com base em princípios constitucionais efetua-se um resgate dos valores da moral e da justiça. Com isso garante-se uma aplicação do Direito mais condizente com a vontade social (ao menos da maioria), implicando numa maior efetividade da norma. Afinal, não é possível negar a correlação entre a Moral e o Direito, principalmente no momento Pós-positivista que se vive.

\footnotetext{
Os juristas, descontentes com uma concepção positivista, estadística e formalista do direito, insistem na importância do elemento moral no funcionamento do direito, no papel que nele desempenham a boa e a má-fé, a intenção maldosa, os bons costumes, a eqüidade [sic], e tantas outras noções cujo aspecto ético não pode ser desprezado. Algumas dessas regras foram promovidas à categoria de princípios gerais do direito e alguns juristas não hesitam em considerá-las obrigatórias, mesmo na ausência de uma legislação que lhes concedesse o estatuto formal de lei positiva, tal como o princípio que afirma os direitos da defesa. (PERELMAN, 2000, p. 298-299).
}

Na fuga de uma concepção puramente positivista do Direito, o que se pretende é afirmar a importância de que a Constituição, enquanto centro do sistema jurídico, 
consolide os valores éticos da sociedade e, a partir do momento em que os confere força normativa, permita uma aplicação do Direito mais condizente com os clamores sociais. Bonavides (2011, p. 291) afirma, inclusive, que os princípios constitucionais representam os princípios gerais do Direito constitucionalizados.

Um apontamento filosófico que indica a conexão entre os princípios fundamentais constitucionais e os elementos da ética é o de que Maritain, um dos filósofos responsáveis pelo teor da Declaração Universal de Direitos Humanos de 1948, desenvolveu um pensamento jusfilofófico baseado na tradicional doutrina tomista. Santo Tomás de Aquino, por sua vez, estudou com profundidade as questões que envolvem a moral e a justiça.

Aliás, o ponto principal estruturador da filosofia de Aquino (2005, p. 529-579) nesse aspecto é a divisão da lei em três espécies: a lei eterna, que traduz a verdade imutável existente em um plano superior; a lei natural, que se refere às coisas existentes no plano humano e ao melhor modo de agir em relação às mesmas, estando presente na razão e concentrando princípios básicos imutáveis; e a lei humana, apta para disciplinar o homem a agir virtuosamente, devendo ser justa, isto é, não contrariar a lei da natureza e a lei divina.

Assim como Aquino, Maritain (1967, p. 59) ressaltou a importância da lei não escrita (ou direito natural) enquanto "[...] uma ordem ou uma disposição que a razão humana pode descobrir, e segundo a qual a vontade humana deve agir a fim de se por de acordo com os fins necessários do ser humano". E foi a partir desta concepção que Maritain (1967, p. 73-74) enumerou em sua obra alguns dos direitos inatos ao ser humano, entre eles: direito à vida, direito à liberdade, direito à integridade corporal, direito à propriedade privada e direito de associação. Além disso, Maritain (1967, p. 9698) apontou os direitos da pessoa cívica, relacionados ao homem como ser político; bem como os direitos da pessoa social, atinentes ao homem em seu espaço de trabalho. Notase a estreita semelhança com os princípios transpostos para a Declaração Universal de Direitos Humanos e que hoje se encontram positivados nos textos constitucionais em geral.

"A Declaração Universal dos Direitos do Homem, que encarna os postulados da lei mais alta e orienta o Direito das nações mais cultas, não obstante as restrições que sofre, é prova incontestável da efetividade do direito natural" (NADER, 2001, p. 172). Afinal, bem se sabe que a Declaração Universal dos Direitos Humanos foi o ponto de partida para um processo de regionalização e positivação dos princípios fundamentais, no qual se transportaram os valores consolidados nos documentos internacionais para as Constituições da maioria dos países (ao menos para aquelas que possam se considerar democráticas). Logo, o movimento Neoconstitucionalista corrobora e confere normatividade aos princípios éticos tradicionalmente afirmados em sociedade. 
efeitos: a total hegemonia e preeminência dos princípios (BONAVIDES, 2011, p. 294).

Percebe-se que o Pós-positivismo consolida uma Nova Hermenêutica Constitucional, conferindo maior liberdade ao intérprete, que passa a ter o dever de considerar na aplicação do Direito que a Constituição e seus princípios ocupam o centro do sistema jurídico. Sob a égide da Nova Hermenêutica, o constitucionalismo de renovação da segunda metade do século XX já permite: reconstrução científica do Direito Constitucional; inauguração do Direito Público como um novo contraponto interpretativo; elaboração de duas teorias hermenêuticas, a teoria da Constituição - mais ampla - e a teoria de interpretação dos direitos fundamentais - mais restrita; a introdução do princípio da proporcionalidade enquanto mecanismo interpretativo constitucional; o reconhecimento da eficácia normativa dos princípios gerais do Direito; e a expansão normativa do Direito Constitucional aos demais ramos jurídicos (BONAVIDES, 2011, p. 598-599).

Vale lembrar que a hermenêutica não serve como instrumento para diversas interpretações, cabendo ao intérprete se manter imparcial, neutro, na tarefa de mediação de conflitos. Corroborada na jusfilosofia, a hermenêutica jurídica implica no questionamento acerca da utilidade, localização, normatividade, utilização e aplicação dos princípios, de modo a fechar e uniformizar a interpretação do Direito. (SANTOS; EHRLICH, 2012, p. 06).

O objetivo fundamental do neoconstitucionalismo é a concretização das prestações materiais prometidas, sendo uma importante ferramenta para a realização da democracia, com um olhar atento sobre os valores principiológicos oriundos da Constituição, evidenciando desta maneira a concretização dos direitos fundamentais. [...] O pós-positivismo deve ser visto como um constitucionalismo transformador, em que o Judiciário tenha papel fundamental. (CAMARGO; DOMINGOS, 2012, p. 77).

De maneira geral, nota-se ainda que devido ao processo de constitucionalização do direito, ocorre uma crescente irradiação dos efeitos das normas ou valores constitucionais aos outros ramos do Direito, chegando a vincular particulares ao dever de obediência aos direitos fundamentais (SILVA, 2008, p. 18). Neste sentido, a tese levantada por Silva (2008, p. 27-28) é de que a constitucionalização do direito no tocante à extensão dos direitos fundamentais às relações privadas não ameaçará a autonomia do direito privado, mas exigirá um modelo mais flexível de aplicação de Direito. Em outras palavras, entende Silva (2008, p. 52) que:

\footnotetext{
Uma das principais mudanças de paradigma que, no âmbito do direito constitucional, foram responsáveis pelo conhecimento de uma constitucionalização do direito e, sobretudo, de um rompimento nos limites de produção de efeitos dos direitos fundamentais somente à relação Estadocidadãos foi o reconhecimento de que, ao contrário do que uma arraigada crença sustentava, não é somente o Estado que pode ameaçar os direitos fundamentais dos cidadãos, mas também outros cidadãos, nas relações horizontais entre si.
}

A alegação de uma eficácia horizontal dos direitos fundamentais, que tem ganhado cada vez mais força no meio jurídico, é fruto dos novos rumos do constitucionalismo. Ocorre que este tem por marco essencial reconhecer a normatividade dos princípios, ao passo que a teoria da eficácia irradiante implica em utilizar os princípios fundamentais como normas vinculantes não só na relação Estado- 
indivíduo, mas também na que se dá entre os particulares. Assim, o Direito Constitucional ganha um espaço cada vez maior no aspecto da aplicação da lei pelos juízes e Tribunais. Essa faceta fica mais evidenciada quando verificada em face da relação entre indivíduos no ambiente Internet.

\section{INTERNET: ORIGENS E COLISÕES DE PRINCÍPIOS}

Ao se iniciar a interação humana no ambiente virtual, passou-se a integrar uma faceta da realidade, a ponto de gerar a virtualidade real. As imagens e os textos que se reproduzem na virtualidade não formam a aparência da experiência, mas constituem a experiência fática. (CASTELLS, 2006, p. 459). Sem adotar o pressuposto de que o ciberespaço, ainda que seja virtualizado, compõe uma faceta da realidade material, não é possível compreender o fenômeno da sociedade informatizada, na qual a Internet desempenha papel de destaque.

Afinal, a Internet decorre do processo de virtualização do computador, no qual este deixou de ser simplesmente uma máquina e, com os programas de software e hardware da informática contemporânea, deu lugar a um espaço de comunicação navegável e transparente baseado em fluxos de informação (LÉVY, 2005, p. 46). Antes que isso ocorresse, houve um gradual processo de evolução tecnológica e científica.

Na década de 1940 foi criada nos Estados Unidos a primeira máquina que pode ser considerada relativamente próxima ao computador, assim como ele é visto hoje, a Eletrical Numerical Integrator and Calculator, que se assemelhava a uma calculadora gigante, com trinta toneladas, ocupando uma sala inteira, sendo que a sua principal função era a de realizar complexos cálculos militares (PAESANI, 2006, p. 21). Com a redução do tamanho dos computadores e a necessidade de se criar um modo virtual de ligação destes, iniciaram-se as pesquisas acerca das redes de conexão.

Daí nasceu a Arpanet, considerada a principal rede precursora da Internet. A Arpanet nasceu numa agência militar de pesquisas ligada ao Departamento de Defesa dos Estados Unidos, a Advanced Research Projects Agency (ARPA), no ano de 1958, visando propiciar novos recursos para a Guerra Fria. Em 1962, referida agência contratou Joseph Licklider, até então pesquisador do Instituto de Tecnologia de Massachusetts (MIT), que estudava a interação entre computadores e usuários (OLIVEIRA, 2011, p. 23).

Em relação ao processo de criação da Internet, outros nomes são relevantes, tanto por oferecerem estrutura para a Arpanet quanto por elaborarem protocolos que viabilizaram a conexão em rede, como Leonard Kleinrock, Paul Baran, Donald Davies, Lawrence Roberts, Robert Taylor, Robert Kahn e Vinton Cerf (OLIVEIRA, 2011, p. 24-25).

Considerando que a Arpanet era restrita a poucos usuários e atraía cada vez mais atenção, começou um movimento nas universidades dos Estados Unidos pela obtenção de uma rede própria. Em 1979 tais universidades ganharam o apoio para atingir tal objetivo da National Science Foundation (NSF), instituição que lançou em 1986 a NSFNet, objetivando interligar redes. A NSFNet estimulou redes regionais de todo o território estadudinense, composta por uma estrutura de conexões que vieram a formar a Internet. Em 1991, passou a ser permitido o uso da rede para fins comerciais, ao passo que, em 1995, ocorreu a transferência estrutural para a iniciativa privada. (OLIVEIRA, 2011, p. 25).

Mas foi com a criação do padrão World Wide Web (WWW), que permite ao usuário ter acesso aos mais variados serviços, sem a necessidade de conhecer inúmeros 
protocolos de acesso, a Internet evoluiu e transformou-se no meio de comunicação em massa que é hoje (PAESANI, 2006, p. 26).

Com efeito, a Internet tem origens militares e acadêmicas: da criação de uma rede militar restrita originaram-se as redes que conectavam pesquisadores das universidades americanas, as quais paulatinamente atingiram a sociedade em geral e, por fim, foram objeto de privatização total. A partir daí, a rede mundial de computadores adquiriu recursos variados, que permitiram uma interação pregressivamente mais intensa entre os usuários.

No entendimento de Castells (2006, p. 67), a sociedade passa por diversos períodos estáveis, pontuados por intervalos na história, e o novo paradigma tecnológico ao qual o homem foi submetido no século XX caracteriza um destes intervalos, no qual a cultura material foi transformada, passando a se organizar em torno da tecnologia da informação.

Tanto é que há quem afirme que o direito virtual compõe uma $5^{\mathrm{a}}$ dimensão de direitos fundamentais, ao lado dos direitos envolvendo a liberdade ( $1^{\mathrm{a}}$ dimensão), a igualdade ( $2^{\mathrm{a}}$ dimensão), a fraternidade ( $3^{\mathrm{a}}$ dimensão) e a biotecnologia ( $4^{\mathrm{a}}$ dimensão) (OLIVO, 2003, p. 332). Nesse sentido, Wolkmer (2003, p. 1-30) salienta que os direitos humanos de quinta geração são voltados para as tecnlogias da informação, do ciberespaço e da realidade virtual em geral. Por outro lado, Peck (2002, p. 26) está entre aqueles que defendem que a Internet apenas deu novo enfoque aos conflitos jurídicosociais. Para Peck (2002, p. 26) a não ser que se entenda por nova dimensão uma maximização de direitos fundamentais tradicionalmente estabelecidos, o direito virtual

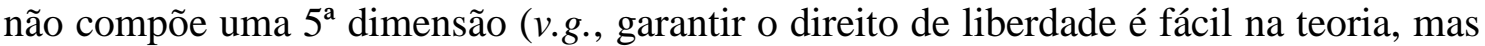
até o surgimento da Internet não existiu um meio de comunicação que possibilitasse o exercício desse direito de maneira maximizada).

Bobbio (2004, p. 38) explica que é consequência natural provocada pelo desenvolvimento social, pela ampliação no conhecimento e pela evolução dos meios de comunicação a necessidade de tutela estatal em outros conflitos antes não regulamentados, ou seja, a ampliação do rol de direitos fundamentais, já que não existem direitos fundamentais por natureza, mas sim direitos que parecem fundamentais a cada época ou cultura.

Independente da postura adotada, percebe-se que na Internet o número de colisões entre princípios tem se intensificado, notadamente devido às novas possibilidades abertas pela rede mundial de computadores. Quer dizer, os princípios fundamentais consolidados na sociedade têm entrado em conflito de maneiras variadas, implicando numa necessidade de maior demanda do Poder Judiciário. Não obstante, em tais demandas o intérprete se depara com a usual ausência de regulamentação específica, precisando lançar mão da normatividade dos princípios para solucionar lides.

A maioria dos conflitos entre particulares que ocorrem no uso da Internet está relacionada ao abuso do direito de liberdade, posto que na rede se intensificaram as possibilidades de seu exercício, especialmente no aspecto da liberdade de expressão. Numa definição técnica, entende-se que a liberdade de pensamento deve ser entendida como a liberdade de adotar determinada atitude intelectual (SILVA, 2006, p. 241); ao passo que a liberdade de expressão ou informação "[...] envolve o direito de passar, receber e buscar informações [...]" (ARAÚJO; NUNES JÚNIOR, 2006, p. 144). Assim, pela liberdade de expressão é exteriorizada a liberdade de pensamento, bem como exercitado o aspecto passivo do direito no sentido de busca de informações.

No início, surgiu por parte dos usuários da Internet a ideia de que as atitudes que nela ocorressem não tinham implicação prática, considerada a virtualidade do ciberespaço, numa defesa que ultrapassava o simples liberalismo (DAOUN; BLUM, 
2000, p. 118). Entretanto, uma corrente mais racional despontou porque "toda liberdade, por mais ampla que seja, encontra limites, que servem para garantir o desenvolvimento ordenado da sociedade e dos direitos fundamentais de qualquer sujeito [...]" (PAESANI, 2006, p. 24). Neste sentido, entendeu a $2^{\mathrm{a}}$ Turma do Superior Tribunal de Justiça: "a Internet é o espaço por excelência da liberdade, o que não significa dizer que seja um universo sem lei e infenso à responsabilidade pelos abusos que lá venham a ocorrer. No mundo real, como no virtual, o valor da dignidade da pessoa humana é um só [...]" (grifo nosso) (BRASIL, 2010).

$\mathrm{O}$ abuso do direito de liberdade vai de encontro a outros bens jurídicos, igualmente tutelados pelo Direito, tais como os direitos de privacidade e de personalidade. O primeiro é composto, pela intimidade, que envolve a esfera mais secreta de cada um, e pela vida privada, referente à externalização desta esfera secreta num espaço privado (MOTTA; BARCHET, 2007, p. 180); enquanto que o segundo envolve a proteção da honra e da imagem, isto é, das qualidades da pessoa e de seu aspecto físico, respectivamente (SILVA, 2006, p. 209). No entender de Paesani (2006, p. 49), "[...] é evidente que o direito à privacidade constitui um limite natural ao direito à informação".

Outro conflito que pode ser vislumbrado é o da violação aos direitos de propriedade intelectual na defesa de uma liberdade de informação irrestrita. Tais direitos dividem-se em morais e patrimoniais, sendo que os primeiros envolvem os direitos de reivindicar a autoria da obra e assegurar a integridade da mesma, ao passo que os segundos se referem sobre as modalidades de utilização de uma obra a título oneroso ou gratuito.

É incontestável que o conceito de propriedade intelectual sofreu mutações e o fator determinante para tanto foi a tecnologia. Sob o enfoque do direito à liberdade, é livre a divulgação de toda informação e o acesso aos dados disponíveis na rede, independente da fonte ou da autoria. Por outro lado, na Internet subsistem os mesmos direitos autorais do que no plano concreto, sendo esta a posição de Gandelman (2007, p. 59), Paesani (2006, p. 67) e Peck (2002, p. 57).

Estes são apenas alguns dos conflitos que usualmente despontam na Internet e que, com frequência crescente, têm sido levados à apreciação do Poder Judiciário. Bem se sabe que o Poder Judiciário não pode se eximir de apreciá-los, conforme assegurado pela Constituição Federal em seu artigo $5^{\circ}$, XXXV: "a lei não excluirá da apreciação do Poder Judiciário lesão ou ameaça a direito" (BRASIL, 2012). Então, não importa se faltam regras específicas acerca de uma ou outra situação jurídica ocorrida no ambiente Internet, caberá ao juiz, no exercício da hermenêutica constitucional, apreciá-los. $\mathrm{O}$ critério, geralmente, envolverá a ponderação e o sopesamento de princípios fundamentais, com base na proporcionalidade:

\footnotetext{
Uma das aplicações mais proveitosas contidas potencialmente no princípio da proporcionalidade é aquela que o faz instrumento de interpretação toda vez que ocorre antagonismo entre direitos fundamentais e se busca desde aí solução conciliatória, para a qual o princípio é indubitavelmente apropriado. [...] Contudo, situações concretas onde bens jurídicos igualmente habilitados a uma proteção do ordenamento jurídico se acham em antinomia, têm revelado a importância do uso do princípio da proporcionalidade (BONAVIDES, 2011, p. 425).
}

Assim, têm sido mais comuns os casos de colisões de princípios do que os de conflitos de regras no tocante às situações jurídicas controversas da Internet. A Nova Hermenêutica Constitucional assume neste ponto uma importância ainda maior, permitindo ao intérprete uma maior liberdade de atuação com base na normatividade 
dos princípios, os quais possuem menor densidade normativa, mas permitem a consubstanciação dos valores ético-jurídicos consolidados na Constituição Federal, atendendo aos interesses da sociedade.

\title{
3. PARTICULARIDADES DA INTERNET: DAS NECESSÁRIAS FLEXIBILIZAÇÃO NORMATIVA E COMPATIBILIDADE MORAL
}

Não obstante a mencionada intensificação e mudanças na configuração dos conflitos, na Internet percebem-se diversas particularidades que implicam, necessariamente, na necessidade de flexibilização normativa e de alta aceitação social (vislumbrada numa alta compatibilidade entre o direito posto e o agir ético esperado dos usuários, aproximando-se o Direito da Moral). Os principais elementos da rede que se enquadram nesta categoria são: desterritorialização, isto é, relativização dos conceitos de espaço e tempo; alto dinamismo, consistente num intenso e inesgotável fluxo de informações; e elevada autonomia de ação, considerados os recursos da rede que possibilitam uma interação ativa dos internautas.

Iniciando pelo aspecto da relativização dos conceitos de espaço e tempo, percebe-se que na Internet as fronteiras temporais e materiais usualmente concebidas em sociedade tornam-se mais difusas. Melhor dizendo, o fato de a Internet consistir numa única grande rede implica na impossibilidade de separação dos conteúdos postados pelo globo.

\begin{abstract}
O novo sistema de comunicação transforma radicalmente o espaço e o tempo, as dimensões fundamentais da vida humana. Localidades ficam despojadas de seu sentido cultural, histórico e geográfico e reintegram-se em redes funcionais ou em colagens de imagens, ocasionando um espaço de fluxos que substitui o espaço de lugares. O tempo é apagado no novo sistema de comunicação já que passado, presente e futuro podem ser programados para interagir entre si na mesma mensagem. O espaço de fluxos e o tempo intemporal são as bases principais de uma nova cultura, que transcende e inclui a diversidade dos sistemas de representação historicamente transmitidos: a cultura da virtualidade real, onde o faz-de-conta vai se tornando realidade. (CASTELLS, 2006, p. 462).
\end{abstract}

Assim, uma própria cultura global tem se formado na Internet, interagindo pessoas de todo o mundo. Estas, em regra, seguem uma espécie de netqueta, baseada nos usos éticos consolidados em sociedade no decorrer dos tempos, muitos deles transformados em princípios constitucionais. Lévy (2005, p. 21) utiliza a expressão desterritorialização para designar a característica referente às mutações nos conceitos de espaço e tempo no ciberespaço:

\footnotetext{
Quando uma pessoa, uma coletividade, um ato, uma informação se virtualizam, eles se tornam "não-presentes", se desterriorializam. Uma espécie de desengate os separa do espaço físico ou geográfico ordinários e da temporalidade do relógio e do calendário. [...] Recortam o espaço-tempo clássico apenas aqui e ali, escapando a seus lugares comuns realistas: ubiquiidade [sic], simultaneidade, distribuição irradiada ou massivamente paralela. [...] A sincronização substitui a unidade de lugar, e a interconexão, a unidade de tempo.
}

É possível, por exemplo, que um pacote de dados enviado por um usuário sediado na China, mas hospedado nos Estados Unidos, tenha como destinatário um usuário do Brasil, ocorrendo uma verdadeira confusão a respeito do momento e do local do ato ilícito causado. No aspecto penal, a confusão é ainda maior - difícil imaginar uma 
solução coerente dos conflitos da lei no espaço e no tempo e, encontrando-a, a punição efetiva seria outro obstáculo - isso sem falar na não aceitabilidade de flexibilização do Direito e solução de conflitos com base em princípios na área penalista (ao menos não para se considerar um ato como crime). Por isso, não há mal em se privilegiar a punição na esfera cível - nela, aliás, será possível solucionar os conflitos mais facilmente, sem o problema de prejuízo à efetividade da aplicação do Direito, utilizando-se sempre que necessário a ponderação de princípios para aplicar a sanção, e a própria tecnologia para executá-la, permitindo o bloqueio de bens e valores do infrator, onde quer que se encontre, respeitando-se os pactos internacionais de mútua colaboração.

Não se pode afirmar que com o reforço do caráter de ultima ratio do direito penal, privilegiando-se a esfera cível, serão solucionados todos os problemas sob o aspecto da aplicação do Direito. Há outras questões tortuosas, a exemplo da usual falta de consenso entre mantenedoras de sites na $W e b$ e os países nos quais elas não possuem sede material. Ou seja, é comum que internautas de um país utilizem sites com sede material exclusivamente em outro país, o que dificulta a atuação estatal no sentido de requerimento de informações e aplicação da lei. No caso, as implicações deste aspecto se dão tanto no âmbito do direito civil quanto no penal. Por outro lado, é mais fácil vislumbrar uma mudança de postura no tocante à efetivação de acordos de colaboração entre as empresas atuantes na Internet e os entes de direito público internacionais. Enfim, questões cíveis costumam ser resolvidas com maior relativização de fronteiras e colaboração entre as partes, seja no âmbito interno, seja no internacional.

Voltando ao cerne do tópico, no exemplo anteriormente mencionado resta claro como o Direito aplicado de forma mais flexível implica em resolver um maior número de conflitos, independentemente do momento e do local da ação, punindo-os de maneira mais eficaz: com a normatividade dos princípios não é possível que qualquer ato que cause ou ameaça causar algum dano a alguém ou à sociedade seja colocado à margem do ordenamento jurídico; além do que tais princípios se encontram expressos nas Constituições da maioria dos países, ao menos naqueles caucados em Estados Democráticos de Direito, facilitando as homologações de sentenças (no Brasil, por exemplo, há o exequatur perante o Superior Tribunal de Justiça, efetuando-se análise do teor da decisão cível condenatória proferida contra brasileiro no estrangeiro e, havendo homologação, cabe execução da sentença sem um outro processo de conhecimento). E na prática, é mais fácil - e nem por isso menos eficaz - a execução da punição cível do ato, pois a própria tecnologia permite a localização de bens e valores (v.g. sistemas de penhora on-line, arquivos de declarações fiscais).

Partindo para o segundo aspecto, na Internet há um alto dinamismo, isto é, um intenso e inesgotável fluxo de informações, que adquire milhões de novos dados a cada segundo. Da mesma forma, se multiplicam diariamente na rede os recursos, os hábitos, os tipos de sites. Assim, o dinamismo da Internet encontra-se em 2 elementos: intenso fluxo de dados e criação constante de novos recursos.

Corrêa $(2000$, p. 08) explica que a Internet proporciona "[...] um intercâmbio de informações sem precedentes na história, de maneira rápida, eficiente e sem a limitação de fronteiras, culminando na criação de novos mecanismos de relacionamento". Ainda, explica Lévy (2003, p. 13) que as telecomunicações geram um dilúvio de informações porque possuem uma natureza exponencial, explosiva e caótica, de modo que cada vez mais aumentam os dados disponíveis, a densidade dos links e os contatos entre os indivíduos.

Hodiernamente, a Internet ocupa na sociedade um grande espaço, uma vez que a população se adaptou aos seus recursos, colocando-os numa posição essencial no tocante às relações jurídico-sociais. Com efeito, "a lógica do funcionamento de redes, 
cujo símbolo é a Internet, tornou-se aplicável a todos os tipos de atividades, a todos os contextos e a todos os locais que pudessem ser conectados eletronicamente" (CASTELLS, 2006, p. 89).

No ciberespaço surgiram novas classificações de dispositivos informacionais, que são o mundo virtual e a informação em fluxo. O primeiro refere-se à disposição de informações em um espaço contínuo, sem estrutura reticulada, enquanto que a segunda envolve a existência de dados em estado contínuo de modificação, que embora sejam dispersos, estão interconectados e podem ser percorridos pelos que tem acesso à rede. (LÉVY, 2003, p. 62). Em outras palavras, no chamado mundo virtual é impossível separar as informações de maneira sistematizada, pois elas estão dispersas e interligadas em uma única grande rede, que, por conta da informação em fluxo, é constantemente alterada.

Mais uma vez, se vislumbra a necessidade de flexibilização normativa: como um Direito estático, com excessiva normatização, conseguirá atingir todas as situações de conflitos presentes na Internet? Afinal, diariamente, surgem novas relações jurídicosociais, variados conflitos que serão levados ao Poder Judiciário. O legislador não conseguiria acompanhar o ritmo de evolução e crescimento da Internet, acabando o ordenamento jurídico por ficar constantemente desatualizado.

Por outro lado, a flexibilização normativa, consistente no uso intenso da Nova Hermenêutica Constitucional, aplicando-se sempre que necessária a força normativa dos princípios enquanto instrumento de solução de colisões. Não somente o Direito será mais dinâmica, atendendo de forma eficaz os litígios decorrentes da rede, como também se mostrará mais compatível com os padrões ético-sociais, o que implica numa maior aceitação das decisões impostas. Afinal, como lembra Bonavides (2011, p. 258):

\footnotetext{
Sem aprofundar a investigação acerca da função dos princípios nos ordenamentos jurídicos não é possível compreender a natureza, a essência e os rumos do constitucionalismo contemporâneo. A normatividade dos princípios representa [...] traço comum a todas aquelas acepções, sendo, por conseguinte, o vínculo unificados das seis formulações enunciadas [...] Os princípios, uma vez constitucionalizados, se fazem a chave de todo o sistema normativo.
}

Finalmente, aponta-se uma última característica da rede, a qual influencia notadamente na necessidade de elevada aceitação social das imposições jurídicas feitas no ciberespaço: elevada autonomia de ação, devido aos diversos, fáceis e gratuitos modos de uso da Internet, permitindo um exercício intensificado das esferas de liberdade. Destaca-se que embora seja fácil bloquear o ilícito de um ou outro usuário, se a rede rejeita uma imposição, encontra um modo de passar por ela - daí ser preciso aceitação da norma imposta.

Quanto à variedade de modos de utilização, em pesquisa do Comitê Gestor de Internet do Brasil, referente ao ano de 2009, detectou-se que entre os usuários brasileiros $88 \%$ faziam uso da rede como meio de pesquisa para busca de informações e serviços, $86 \%$ para o lazer, $14 \%$ para serviços bancários e $71 \%$ para fins educacionais (BRASIL, 2010, p. 250-262). Isso sem falar em um dos serviços proporcionados pela rede que ganha a cada dia mais força, o do comércio eletrônico, sendo que em 2009, no Brasil, 19\% dos indivíduos que já haviam acessado a Internet fizeram compras on-line (BRASIL, 2010, p. 299).

Devido aos recursos e formas variados, percebe-se uma ampla possibilidade de exercício da autonomia na rede mundial de computadores: a pessoa pode adquirir produtos de todo o mundo com facilidade, manifestar o seu pensamento como bem entender, buscar toda e qualquer informação. Os direitos antes tradicionalmente 
garantidos, na rede mundial de computadores, ganharam efetiva possibilidade de exercício: uma coisa é garantir a liberdade de expressão numa sociedade onde os meios de comunicação são onerosos, outra é dar tal garantia quando existe uma rede com espaços para divulgação gratuita de informações; da mesma forma, garantir o acesso à cultura global quando é preciso locar um filme ou comprar um CD é diferente de garantir tal direito se na rede é possível disponibilizar todos estes conteúdos sem custo para o usuário. O mundo está mudando e o Direito deve acompanhar tais mudanças, flexibilizando e conferindo novas interpretações aos seus princípios.

Se isso não acontecer, a tendência é que se repitam na rede mundial de computadores movimentos contrários à ação do Estado. Recentemente, por determinação da justiça norte-americana, foi fechado o site do Megaupload, que disponibilizava download de arquivos variados (filmes, músicas, entre outros) (MAGAUPLOAD, 2012). O site permanece fechado, mas em poucos dias os internautas se organizaram para remanejar os arquivos bloqueados para outros sites e programas, de modo que a decisão judicial não alterou em nada o funcionamento da rede. Trata-se de uma decisão não aceita socialmente, que implicou numa multiplicação dos arquivos pela rede, praticamente impossibilitando que a justiça consiga impedir a realização dos downloads pelos usuários. A questão sobre o direito à propriedade intelectual é mais polêmica (social e juridicamente) do que demonstra o caso, mas, por uma questão metodológica, não será aprofundada.

A dimensão ético-jurídica sempre esteve presente, mas, como lembra Dupas (2000, p. 88), as sociedades pós-modernas têm se libertado das amarras dos valores de referência, ao mesmo tempo demandando cada vez mais por ética e pelos preceitos morais. Não há um único Direito, uma única justiça, para sempre: é preciso entender que as mudanças exigem dos intérpretes uma aplicação variável do Direito, condizente com a vontade social.

Utilizando-se da ponderação de princípios, é possível aproximar mais facilmente o Direito aplicado das necessidades da sociedade, criando na Internet um ambiente democrático de exercício de liberdades, sem desrespeitar eventuais princípios fundamentais colidentes. A aceitação social implica numa maior eficácia das punições necessárias quanto aos atos no ciberespaço, pois contarão com o apoio de milhões de internautas, por exemplo, com a utilização de centrais virtuais de denúncia.

\section{SOLUÇÕES DO NEOCONSTITUCIONALISMO PARA OS CONFLITOS DE PRINCÍPIOS FUNDAMENTAIS NA INTERNET}

Assim como destacado na introdução, retoma-se o fato de que a hermenêutica constitucional ganhou evidência a partir da década de 1950, estando desde então em constante ascensão, sendo também este o contexto da hermenêutica dos direitos fundamentais (BONAVIDES, 2011, p. 595). Nas colisões de princípios fundamentais na Internet geralmente será necessário utilizar as regras da Nova Hermenêutica, que envolvem a ponderação, baseando-se em critérios como proporcionalidade $\mathrm{e}$ razoabilidade. Vale retomar os principais pontos da Nova Hermenêutica, conforme Bonavides (2011, p. 606-608):

Há na Constituição normas que se interpretam e normas que se concretizam. A distinção é relevante desde o aparecimento da Nova Hermenêutica, que introduziu o conceito novo de concretização, peculiar à interpretação de boa parte da Constituição, nomeadamente dos direitos fundamentais e das cláusulas abstratas e genéricas do texto constitucional. Neste são usuais preceitos normativos vazados em fórmulas amplas, vagas e maleáveis, cuja 
aplicação requer do intérprete uma certa diligência criativa, complementar e aditiva para logras a completude e fazer a integração da norma na esfera da eficácia e juridicidade do próprio ordenamento. Na Velha Hermenêutica, regida por um positivismo lógico-formal, há subsunção; em a Nova Hermenêutica, inspirada por uma teoria material de valores, o que há é concretização; ali, a norma legal, aqui, a norma constitucional; uma interpretada, a outra concretizada. [...] Os métodos tradicionais, a saber, gramatical, lógico, sistemático e histórico, são de certo modo rebeldes a valores, neutros em sua aplicação, e por isso mesmo impotentes e inadequados para interpretar direitos fundamentais. Estes se impregnam de peculiaridades que lhes conferem um caráter específico, demandando técnicas ou meios interpretativos distintos, cuja construção e emprego gerou a Nova Hermenêutica. [...] A partir daí se coloca, obviamente, o recurso ao princípio da proporcionalidade, que também serve de apoio à metodologia da Nova Hermenêutica.

Assim, a atuação jurisdicional hoje deve ser baseada na qualidade de centro do sistema normativo conferida à Constituição Federal. A partir daí, a normatividade dos princípios implica na possibilidade de solução de conflitos baseada exclusivamente neles. Considerando a regra de que os princípios não se anulam, mas colidem, o critério da proporcionalidade se mostra fundamental.

Por sua vez, as principais vantagens que o Neoconstitucionalismo traz à aplicação da lei na Internet são: maior compatibilidade entre o Direito posto e o agir moral consolidado em sociedade e flexibilização do Direito adequada ao dinamismo da rede. O caráter normativo dos princípios, aliado ao crescente reconhecimento da eficácia horizontal dos direitos fundamentais implica também na possibilidade de utilização do critério em toda e qualquer relação jurídica, envolvendo o Estado ou exclusivamente os particulares.

Iniciando uma explicação sobre como o Neoconstitucionalismo consubstancia na aplicação do Direito a realização mais próxima de um sentimento de justiça, destacase que ele traz a tona como principal fundamento os valores consolidados em sociedade através dos tempos, com um conteúdo ético comum. Aliás, a legitimidade da Constituição e dos direitos fundamentais decorre da tradução em uma tábua de valores, que representam a ordem democrática do Estado de Direito, de modo que a eficácia das regras constitucionais e a estabilidade dos princípios do ordenamento jurídico compõem uma teoria material da Constituição (BONAVIDES, 2011, p. 596). Melhor explicando, os princípios consolidados no texto constitucional não surgiram do nada, decorrem de uma formação histórico-filosófica, na qual inicialmente a Moral se confundia com o próprio Direito, representado pelo valor justiça. Estas são as bases do Direito Natural, o qual foi resgatado na fase Pós-positivista.

As Constituições fazem no século XX o que os Códigos fizeram no século XIX: uma espécie de positivação do Direito Natural, não pela via racionalizadora da lei, enquanto expressão da vontade geral, mas por meio dos princípios gerais, incorporados na ordem jurídica constitucional, onde logram valoração normativa suprema, ou seja, adquirem a qualidade de instância juspublicística primária, sede de toda a legitimidade de poderes. Isto, por ser tal instância a mais consensual de todas as intermediações doutrinárias entre o Estado e a Sociedade (BONAVIDES, 2011, p. 293).

Claro, os valores éticos muito evoluíram e continuarão mudando através dos tempos. O próprio processo de criação de novas tecnologias (informática e genética, por exemplo) obriga o homem a repensar diariamente seus valores, suas pretensões para o futuro. Isso não significa que certa base comum se perdeu, pelo contrário, determinados 
valores éticos fundamentais que compõem o Direito Natural e os princípios fundamentais normatizados permanecem muito vivos no âmago da sociedade.

[...] a ética não é alheia ou indiferente às condições históricas e políticas, econômicas e culturais da ação moral. Conseqüentemente [sic], embora do ponto de vista da sociedade que a institui uma ética seja sempre considerada universal (universal porque seus valores são obrigatórios para todos os seus membros), de fato, toda ética está em relação com o tempo e a história, transformando-se para responder a exigências novas da sociedade e da cultura, pois somos seres históricos e culturais e nossa ação se desenrola no tempo. (CHAUÍ, 2005, p. 309).

Os princípios constitucionais aplicados com força normativa permitem $\mathrm{o}$ resgate dos valores ético-sociais mais comuns, que devem ser diariamente resgatados. $\mathrm{Na}$ Internet, isso significa compatibilizar as condutas que vêm se firmando numa autodisciplina com as decisões judiciais sobre conflitos na rede.

A Internet é um espaço propício para o exercício das aptidões de consciência e responsabilidade, isto é eticidade. Isto se dá porque a rede proporciona recursos aos usuários para manifestarem seu pensamento e denunciarem violações às leis morais fundamentadoras dos princípios fundamentais constitucionalmente assegurados.

As expressões correntes utilizadas pela doutrina para designar este comportamento esperado do internauta são autodisciplina e autorregulamentação. Conforme Paesani (2006, p. 19), a adequação da sociedade a uma autorregulamentação é um desafio atual, bem como o exercício da liberdade responsável sem os excessos da intervenção estatal. De acordo com Peck (2002, p. 26), a criação de legislação específica não atenderia aos fins almejados pela sociedade da informação, que sofre com a relativização dos conceitos de espaço e tempo, motivo pelo qual há uma tendência de estabelecimento da disciplina jurídica através da autorregulamentação.

Com efeito, confere-se uma máxima eficácia às prerrogativas constitucionais, bastando para tanto "[...] apenas uma atividade hermenêutica constitucionalizada pelo intérprete jurídico e, assim, a extração da verdadeira essência da dignidade da pessoa humana, revelando o real valor do pensamento constitucional, qual seja a igualdade entre os indivíduos" (CAMARGO; DOMINGOS, 2012, p. 77).

Do mesmo modo, a autodisciplina influencia a autoregulamentação, pois reflete o caráter dinâmico e interativo da rede mundial de computadores: é preciso proporcionar um Direito que seja tão maleável quanto as inovações constantes da Internet, permitindo uma maior efetividade na sua aplicação. Isso é permitido na atual sistemática de decisões judiciais, o que reflete o

[...] princípio da unidade do sistema jurídico, que é, numa visão juspublicística onde se incorporam as mais recentes conquistas metodológicas da Nova Hermenêutica, o mesmo princípio da unidade da Constituição. Mas, obviamente, segundo uma perspectiva de eficácia e normatividade cuja abrangência se estende a todas as partes do ordenamento, constituindo ao mesmo passo a suma do Direito Positivo vigente (BONAVIDES, 2011, p. 275).

Não se trata de promover um invencionismo, sob pena de não se garantir que a aplicação do Direito seja adequada, justa. O que a sociedade informatizada exige é uma flexibilização normativa, um tratamento maleável e justo das colisões de princípios, compatibilizando as decisões judiciais com as necessidades que são manifestadas pelos internautas na rede. Tudo isso está abrangido pelas possibilidades do 
Neoconstitucionalismo, movimento jurídico apto a aproximar cada vez mais o Direito da sociedade.

O que a hermenêutica jurídico-constitucional, pretende dos profissionais do direito é que tenham em mente que a atribuição de um sentido à norma não é mesma coisa que a livre criação de um sentido para norma. Exige-se a jurisdição conforme a Constituição, ou seja, que o intérprete não perca a noção de que o Direito é um sistema de regras e de princípios e a sua correta interpretação não admite princípios sem regras e nem regras sem princípios. (SANTOS; EHRLICH, 2012, p. 10).

O exercício interpretativo se mostra o caminho mais adequado para a realização da justiça no ciberespaço, permitindo a criação de um ambiente salutar na Web, o que é de interesse coletivo. Por isso, na atividade hermenêutica é preciso cautelas, atentandose sempre para a coerência e uniformidade das decisões. Com efeito, a sociedade sentirá a segurança de que a falta de normatização específica não implica numa ineficácia jurídica.

O magistrado deve ter um comportamento ativo, resguardados os devidos limites, fazendo com que sua decisão não fuja dos parâmetros oriundos da atividade jurisdicional, e, utilizando-se da razoabilidade e da proporcionalidade, contribuindo para o alcance do objetivo almejado por todos, a justiça. [...] (CAMARGO; DOMINGOS, 2012, p. 73).

Então, as principais vantagens do estabelecimento de um sistema de aplicação normativa baseado em princípios em relação à Internet são a de criar um ambiente compatível com a vontade social, no qual a atualização jurídica será um item menos necessário do que num sistema fechado de normas. Afinal, a Constituição tem um conteúdo que pode se amoldar às necessidades da sociedade, seu texto não tem um conteúdo delimitado ou fixo, podendo as interpretações variarem através dos tempos.

A cada época são necessárias diferentes interpretações ao ordenamento
jurídico, pois apesar de o texto constitucional ser relativamente estático, o ser
humano e a coexistência em sociedade são dinâmicos. A Constituição
Brasileira de 1988, em todos estes anos de existência, tem seu texto e seu
núcleo, salvo exceções, imutáveis, por isso a interpretação de suas entrelinhas
deve ser contextualizada, cabendo esta difícil tarefa ao aplicador do Direito.
Neste sentido, surge o fenômeno das mutações constitucionais, o qual mostra
a dinamicidade das normas jurídicas. Através deste método são buscados
novos sentidos de maneira informal (não prevista dentro das formalidades do
texto constitucional). Estes novos sentidos sucedem-se através dos fatos
históricos, da aplicação reiterada de certa decisão judicial ao caso concreto
(jurisprudência) e das correntes doutrinárias formadas em torno de assunto de
interesse coletivo. (CAMARGO; DOMINGOS, 2012, p. 73).

A título de exemplo, pode-se citar a evolução da interpretação do alcance do disposto no artigo $5^{\circ}$, XII, da $\mathrm{CF}$, em face do direito à intimidade e à privacidade: "é inviolável o sigilo da correspondência e das comunicações telegráficas, de dados e das comunicações telefônicas, salvo, no último caso, por ordem judicial, nas hipóteses e na forma que a lei estabelecer para fins de investigação criminal ou instrução processual penal" (BRASIL, 2012). Inicialmente, tinha-se o entendimento de que somente poderia haver a quebra do sigilo das comunicações telefônicas, depois passou-se a entender que a quebra do sigilo também acobertaria as comunicações de dados para, atualmente, terse o entendimento de que nenhum direito ou garantia individual é absoluto, passando a 
admitir, mediante a análise do caso concreto, a quebra do sigilo de qualquer meio de comunicação, inclusive a epistolar, com alicerce no princípio da proporcionalidade.

Antigamente, seria comum ouvir o argumento de que os princípios fundamentais não poderiam servir de instrumento decisivo para a decisão de litígios entre particulares. No entanto, esta posição tem caído por terra devido à crescente aceitação da eficácia horizontal dos direitos fundamentais, que sujeita os particulares ao respeito aos direitos fundamentais de terceiros. Isto decorre de um processo de constitucionalização do Direito, afinal, a Constituição Federal é o centro do sistema jurídico no Pós-positivismo.

Era usual afirmar que os direitos fundamentais se dirigiam exclusivamente às relações Estado-particular. Ocorre que o argumento nem ao menos é compatível com o texto constitucional porque a Constituição brasileira dá a entender que suas regras se estendem às relações entre particulares, por exemplo, quando disciplina a liberdade de expressão (artigo $5^{\circ}, \mathrm{IV}$ ), a qual corresponde o direito de resposta (artigo $5^{\circ}, \mathrm{V}$ ), sendo muito mais comum a aplicação no âmbito da relação entre indivíduos (SILVA, 2008, p. 22).

No âmbito da Internet, entendendo que o usuário tem o direito de exercer suas liberdades fundamentais, mas também a preservar os demais direitos inerentes à sua condição de pessoa, há de se compreender que nas relações de um internauta com relação ao outro, bem como destes com as empresas que atuam na rede mantendo sites, existe um dever de respeito aos direitos fundamentais. Na verdade, a questão da eficácia horizontal dos direitos fundamentais ganha relevância se considerado o papel de destaque desempenhado pelas mantenedoras de sites na Web, tanto na atuação voltada para o e-commerce quanto na relativa à administração de sites de relacionamentos.

Essas corporações, ainda que privadas, alcançam uma posição de dominação, sobretudo por meio de concentração financeira, que lhes confere um tal poder de decisão nas suas relações com os indivíduos que qualquer relação jurídica entre ambos, a despeito de se fundar aparentemente na autonomia da vontade, é, na verdade, uma relação de dominação, que ameaça, tanto quanto a atividade estatal, os direitos fundamentais dos particulares (BONAVIDES, 2011, p. 52-53).

Então, na rede mundial de computadores a tendência é a de que os princípios fundamentais sejam utilizados para resolver toda e qualquer espécie de litígio, independente do envolvimento estatal. No tocante às grandes corporações, esta é uma tendência que tem se manifestado - são frequentes as decisões judiciais contra sites da Web baseadas em tais princípios, muitas vezes estendendo responsabilidades.

Por exemplo, no Recurso Especial n. 1.117.622/RO, lançando base no princípio da dignidade da pessoa humana, inerente às crianças e aos adolescentes que estavam sendo vítimas da constante criação de páginas ofensivas, o Superior Tribunal de Justiça reconheceu a existência de uma responsabilidade das mantenedoras das redes sociais, qual seja: quem viabiliza e estimula a criação de páginas é tão responsável pela manutenção do conteúdo quando os usuários cadastrados, não só devendo retirar conteúdos ofensivos do ar, mas impedi-los de chegar na rede (BRASIL, 2010).

Silva (2008, p. 148), ao tratar do relevante tema da eficácia irradiante dos direitos fundamentais, aponta que é possível aplicar os direitos fundamentais aos particulares de forma indireta ou direta; sendo que em certas situações somente uma solução direta pode ser adequada, o que ocorre sempre que

[...] não há mediação legislativa ou que a atividade legislativa se tenha mostrado insuficiente. É na aplicação direta, portanto, que os problemas se 
tornam mais agudos, pois é nesses casos que os direitos fundamentais mais diretamente se chocam com a autonomia privada.

A autonomia privada na Internet, como visto no presente artigo, adquire novos rumos: o exercício das liberdades individuais é muito mais intenso, adquire facetas variadas. Se, por um lado, as colisões de princípios se tornam mais frequentes; por outro lado, é elogiável a existência de um espaço tão democrático como a Internet. Então, é dever dos profissionais do Direito trabalharem para criar na rede um sistema jurídico adequado às suas necessidades. O Pós-positivismo, aliás, abriu as portas para que tal dever seja desempenhado com maestria, de modo a garantir a realização da justiça na Internet, sem prejudicar o seu caráter libertário.

\section{CONSIDERAÇÕES FINAIS}

Foi possível compreender que o Direito não é estático, passando por mudanças de suas concepções através dos tempos. No âmbito do Direito Constitucional, os marcos essenciais no tocante à aplicação do Direito envolveram as diversas concepções da função dos princípios no sistema constitucional. Na fase naturalista, os princípios eram mandamentos gerais da razão, mas não possuíam força normativa; ao passo que na fase positivista os princípios eram declarados, mas apenas como bases subordinadas às regras do sistema jurídico. Somente na pós-positivista que os princípios assumiram o papel que lhes era devido, adquirindo a mesma força normativa das regras, passando a Constituição a ocupar o centro do sistema jurídico. Dentro deste novo contexto, os Tribunais cada vez mais têm se utilizado dos princípios enquanto instrumento basilar de suas decisões.

Se não fosse por esta acentuada mudança no modo como se vê e se aplica o Direito, dificilmente seria possível afirmar a possibilidade de um sistema jurídico flexível, adequado ao dinamismo social que tem se intensificado. Com efeito, o fato de hoje a sociedade viver a era da informatização contribui diretamente para que a dinâmica das relações sociais ganhe nova tônica. Afinal, a sociedade informatizada é muito mais global, veloz, intensa, variável e aberta as ingerências do que qualquer outra na histórica tenha sido.

A principal tecnologia da era informatizada é a Internet, que hoje se encontra disponível não só para computadores, mas também para celulares, tablets, notebooks, televisores, entre outros equipamentos; sendo o seu sinal transmitido por modos variados, inclusive por ondas de sinal em locais públicos (tecnologia Wi-fi). Na rede mundial de computadores, as colisões de princípios se intensificaram, ganharam enfoques diversos, ocasionando uma busca de soluções pelo Poder Judiciário marcada inicialmente por alguns problemas, como ausência de normatização específica e dificuldades de imposição do Direito, notadamente devido às particularidades da Web.

Entretanto, ao menos a título de apontamento introdutório de um estudo que tem muito o que se aprofundar, afirma-se que o Neoconstitucionalismo possibilita que a aplicação do Direito às colisões de princípios em face da violação de bens jurídicos tutelados no ambiente Internet seja justa, condizente com os interesses sociais e dotada de dinamismo. Com efeito, a Nova Hermenêutica Constitucional abre novos campos para os operadores do Direito, apresentando soluções a problemas que há alguns anos já vem perturbando a comunidade jurídica. Se, por um lado, a flexibilização normativa tem todas estas vantagens; por outro lado, o intérprete deverá sempre agir com cautela, ponderando de maneira coerente nas suas decisões, de modo a conferir segurança jurídica ao sistema mais aberto, permitindo a manutenção do caráter democrático e livre da Internet. 


\section{REFERÊNCIAS}

ALEXY, Robert. Teoria dos Direitos Fundamentais. Tradução Virgílio Afonso da Silva. 2. ed. São Paulo: Malheiros, 2011.

AQUINO, Santo Tomás de. Suma Teológica. Tradução Aldo Vannucchi e Outros. Direção Gabriel C. Galache e Fidel García Rodríguez. Coordenação Geral CarlosJosaphat Pinto de Oliveira. Edição Joaquim Pereira. São Paulo: Loyola, 2005. v. VI, parte II, seção II, questões 57 a 122.

ARAÚJO, Luiz Alberto David; NUNES JÚNIOR, Vidal Serrano. Curso de Direito Constitucional. 10. ed. São Paulo: Saraiva, 2006.

BARROSO, Luís Roberto. Interpretação e Aplicação da Constituição. São Paulo: Saraiva, 2003.

BOBBIO, Norberto. A Era dos Direitos. Tradução Celso Lafer. 9. ed. Rio de Janeiro: Elsevier, 2004.

BONAVIDES, Paulo. Curso de direito constitucional. 26. ed. São Paulo: Malheiros, 2011.

BRASIL. Superior Tribunal de Justiça. Recurso Especial n. 1117633/RO. Relator: Herman Benjamin. Brasília, 09 de março de 2010. Disponível em: www.stj.gov.br. Acesso em: 24 fev. 2012.

Constituição da República Federativa do Brasil, de 5 de outubro de 1988.

Diário Oficial da União, Poder Legislativo, Brasília, DF, 5 out. 1988, p. 1, anexo.

Disponível em:

<http://www.planalto.gov.br/ccivil_03/constituicao/constitui\%C3\%A7ao.htm>. Acesso em: 10 fev. 2012.

Ministério das Comunicações e o Ministério da Ciência e Tecnologia. Comitê Gestor da Internet no Brasil. Pesquisa sobre o Uso das Tecnologias da Informação e da Comunicação no Brasil em 2009. São Paulo: Comitê Gestor da Internet no Brasil, 2010. Disponível em: <http://www.cetic.br>. Acesso em: 27 jan. 2012.

CAMARGO, Daniel Marques de; DOMINGOS, Fernanda Cristina Rosseto. Ativismo Judicial: limites, possibilidades e reflexos na efetivação de direitos humanos fundamentais. In: SIQUEIRA, Dirceu Pereira; SANTOS, Murilo Angeli Dias dos. Estudos contemporâneos de hermenêutica constitucional. Birigui: Boreal, 2012. p. 67-85.

CASTELLS, Manuel. A Sociedade em Rede. 9. ed. São Paulo: Paz e Terra, 2006. v. 1.

CHAUÍ, Marilena. Convite à Filosofia. 13. ed. São Paulo: Ática, 2005.

CORRÊA, Gustavo Testa. Aspectos Jurídicos da Internet. São Paulo: Saraiva, 2000. 
DAOUN, Alexandre Jean; BLUM, Renato M. S. Opice. Cybercrimes. In: DE LUCCA, Newton; SIMÃO FILHO, Adalberto (Coord.). Direito \& Internet: Aspectos Jurídicos Relevantes. Bauru: Edipro, 2000. p. 117-129.

DUPAS, Gilberto. Ética e Poder na Sociedade da Informação. São Paulo: UNESP, 2000.

GANDELMAN, Henrique. De Gutenberg à Internet: Direitos Autorais das Origens à Era Digital. 5. ed. São Paulo: Record, 2007.

LÉVY, Pierre. Cibercultura. Tradução Carlos Irineu da Costa. 2. ed. São Paulo: Editora 34, 2003.

O que é virtual? Tradução Paulo Neves. São Paulo: Editora 34, 2005.

MARITAIN, Jacques. Os Direitos do Homem e a Lei Natural. 3. ed. Rio de Janeiro: Livraria José Olympio Editora, 1967.

MEGAUPLOAD. Notice. Disponível em: <http://www.megaupload.com>. Acesso em: 24 fev. 2012.

MOTTA, Sylvio; BARCHET, Gustavo. Curso de Direito Constitucional. Rio de Janeiro: Elsevier, 2007.

NADER, Paulo. Filosofia do Direito. 10. ed. Rio de Janeiro: Forense, 2001.

OLIVEIRA, Marcos de. Nasce a Internet. Revista Fapesp. São Paulo, ano XVII, n. 180, p. 23-25, fev. 2011.

OLIVO, Luís Carlos Cancellier de. Os "Novos" Direitos enquanto Direitos Públicos Virtuais na Sociedade da Informação. In: WOLKMER, Antônio Carlos; LEITE, José Rubens Morato (Org.). Os "Novos" Direitos no Brasil: Natureza e Perspectivas. São Paulo: Saraiva, 2003. p. 319-353.

PAESANI, Liliana Minardi. Direito e Internet: Liberdade de Informação, Privacidade e Responsabilidade Civil. 3. ed. São Paulo: Atlas, 2006.

PECK, Patrícia. Direito Digital. São Paulo: Saraiva, 2002.

PERELMAN, Chaïm. Ética e Direito. Tradução Maria Ermantina Galvão. São Paulo: Martins Fontes, 2000.

SANTOS, Murilo Angeli Dias dos; EHRLICH, Priscila Aparecida. O que é isto - a Hermenêutica Constitucional? In: SIQUEIRA, Dirceu Pereira; SANTOS, Murilo Angeli Dias dos. Estudos contemporâneos de hermenêutica constitucional. Birigui: Boreal, 2012. p. 1-11.

SILVA, José Afonso da. Curso de Direito Constitucional Positivo. 25. ed. São Paulo: Malheiros, 2006. 
SILVA, Virgílio Afonso da. A Constitucionalização do Direito: os direitos fundamentais nas relações entre particulares. São Paulo: Malheiros, 2008.

WOLKMER, Antonio Carlos. Introdução aos fundamentos de uma teoria geral dos "novos" direitos. In: WOLKMER, Antônio Carlos; LEITE, José Rubens Morato (Org.). Os "Novos" Direitos no Brasil: Natureza e Perspectivas. São Paulo: Saraiva, 2003. p. $1-30$. 